\title{
Erratum to: Clinical relevance of conus medullaris and dural sac termination level with special reference to sacral hiatus apex: anatomical and MRI radiologic study
}

\author{
Ashraf Youssef Nasr ${ }^{1}$
}

Published online: 2 January 2017

(C) Japanese Association of Anatomists 2016

\section{Erratum to: Anat Sci Int}

DOI 10.1007/s12565-016-0343-0

The author would like to correct the errors in the original publication of the article. The corrected details are given below for your reading.

In the abstract section, the word "delete" should be removed in the sentence "The linear distances between the CMT, DST and SHA... membrane were also measured". The $P$ value should be " $(P>0.05)$ ", in the sentence "In the MRI study, the mean vertebral ...".

The last sentence in the first paragraph beneath the heading "Material and methods" on page 2 should be "The male and female patients who underwent these MRI studies and who satisfied the inclusion criteria were enrolled in the study and classified into six age groups as follows: $<20$ years (10 patients); $20-29$ years (20 patients); $30-39$ years (20 patients); 40-49 years (20 patients); 50-59 years (20 patients); $\geq 60$ years (10 patients)".

Also, Fig. 2 is a duplicate of Fig. 3. The correct Fig. 2 is placed in the following page.

The online version of the original article can be found under doi: 10.1007/s12565-016-0343-0.

Ashraf Youssef Nasr

ashrafnaeem2013@gmail.com

1 Anatomy Department, Faculty of Medicine, Zagazig

University, Zagazig, Egypt 
a Distribution of the vertebral level of conus medullaris termination at age group $<20$ years-old using MRI (\%)

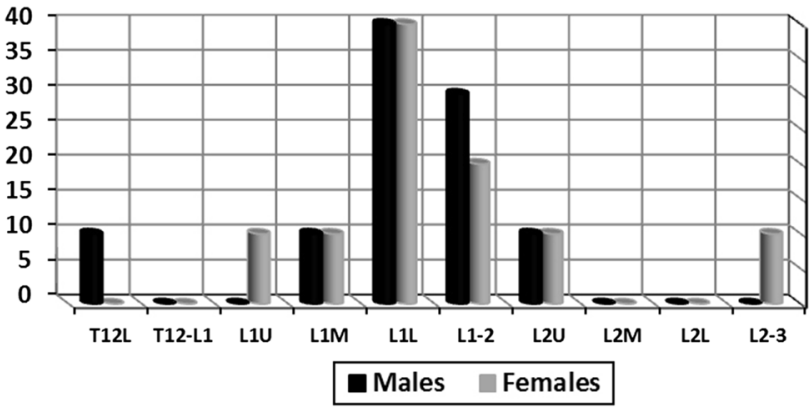

C Distribution of the vertebral level of conus medullaris termination at age group 30 - 39 years old using MRI (\%)

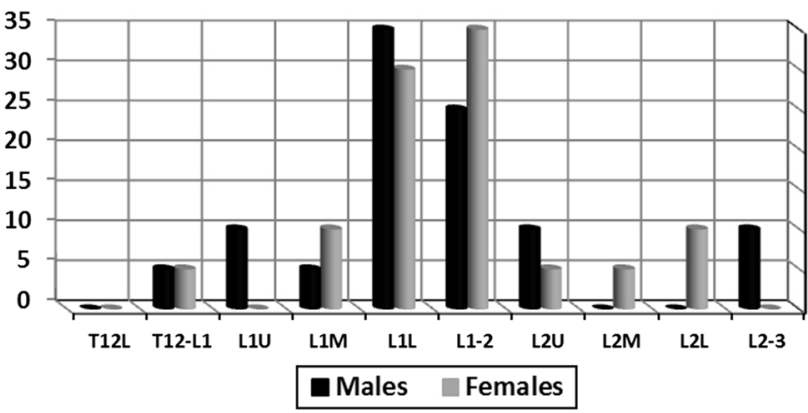

e Distribution of the vertebral level of conus medullaris termination at age group 50 - 59 years-old using MRI (\%)

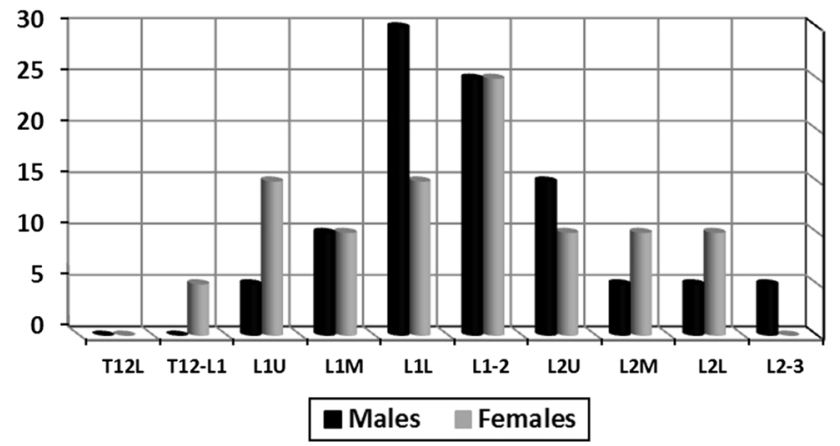

b Distribution of the vertebral level of conus medullaris termination at age group 20 - 29 years-old using MRI (\%)

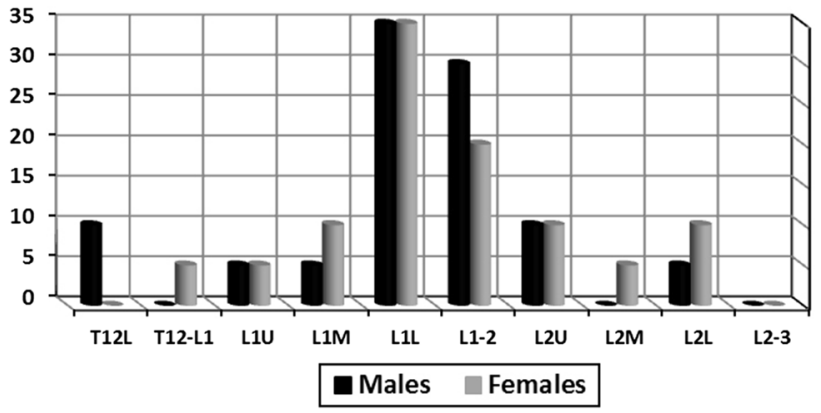

d Distribution of the vertebral level of conus medullaris termination at age group $\mathbf{4 0}$ - 49 years-old using MRI (\%)

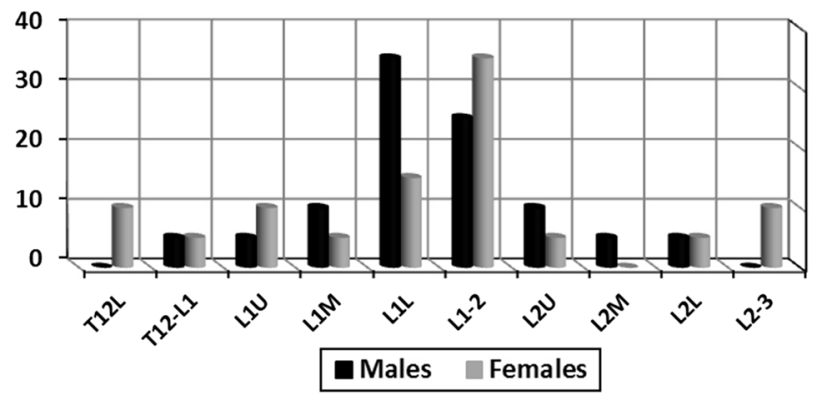

f Distribution of the vertebral level of conus medullaris termination at age group $>60$ years-old using MRI (\%)

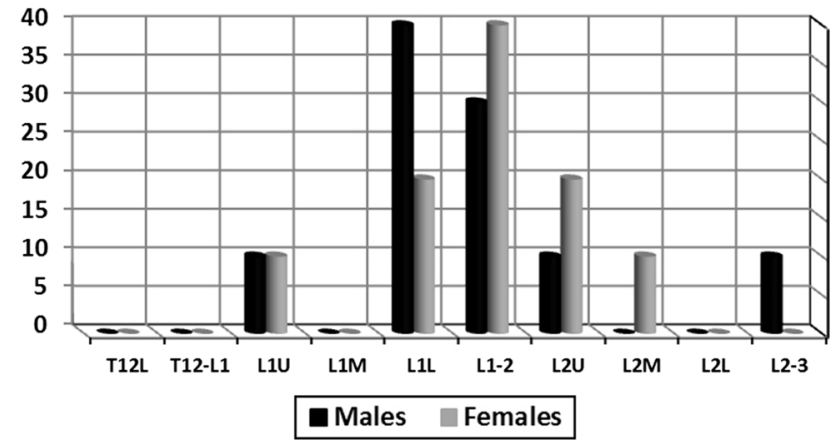

Fig. 2 Frequency of the CMT at different vertebral levels in both female and male patients in the different age groups based on magnetic resonance imaging (MRI). Each vertebra was divided into three equal parts: upper $(U)$, middle $(M)$ and lower $(L)$ 